\title{
O duro ofício de viver
}

[ The hard job of living

\section{Emerson Tin ${ }^{\mathrm{x}}$}

CABRAL, Cleber Araújo (Org.) Mares interiores: correspondência de Murilo Rubião $\nLeftarrow$ Otto Lara Resende. Belo Horizonte: Autêntica Editora; Ed. UFMG, 20I6, $222 \mathrm{p}$.

Cleber Araújo Cabral

MARES
INTERIORES
CORRESPONDÊNCIA
DE
MURILO
RUBIÃO
$\&$
OTTO LARA
RESENDE

eutêntica (roroenufurmg
É de longa tradição, na literatura ocidental, a comparação da vida a uma embarcação à deriva no mar, ao sabor das intempéries. Basta lembrar que Ernst Robert Curtius dedicou à chamada "metáfora náutica" algumas páginas de seu clássico Literatura europeia e Idade Média latina. Não à toa, tem sido imagem querida para dar nome a obras que pretendem dar conta da trajetória de uma existência. Tal é o que vemos, por exemplo, em A barca de Gleyre, de Monteiro Lobato, título que não só associa a metáfora náutica à troca epistolar entre o escritor taubateano e o mineiro Godofredo Rangel, mas também alude à célebre tela do suíço Marc-Charles-Gabriel Gleyre.

TIN, Emerson. O duro ofício de viver. Revista do Instituto de Estudos Brasileiros, Brasil, n. 67, p. 229-233, ago. 2017.

DOI: http://dx.doi.org/Io.II606/issn.23I6-90IX.voi67p229-233

I Faculdades de Campinas (Facamp, Campinas, SP, Brasil). 
É sintomático, assim, que Cleber Araújo Cabral, ao organizar e anotar a correspondência de Murilo Rubião e Otto Lara Resende, tenha a ela recorrido, pescando, de modo sagaz, a expressão "mares interiores", que aparece primeiramente em carta de Murilo Rubião (datada de 5 de agosto de I948) e reaparece na de Otto Lara Resende (datada de 2 de dezembro do mesmo ano), para nomear o livro que a Autêntica Editora e a Editora da UFMG publicaram em 2016.

Justifica-se muito bem a escolha da expressão. Afinal, nesse grande oceano da existência, a correspondência aparece, muitas vezes, como a tábua de salvação ou o farol que guia os desorientados navegantes para um porto seguro. Estando os correspondentes entre aflições, "mistérios da vida" (carta 20), "mergulhado num mar de dívidas, eu, que nunca soube nadar nem em felicidade!" (carta I8), "úmido de melancolia" (carta 22), as cartas que vêm e que vão aparecem como "um consolo, um aviso aos navegantes, réstia de farol entrevisto no negro mar alto das dívidas bancárias" (carta 2I).

A minuciosa reconstituição dessa correspondência permite-nos um vislumbre de duas existências de carne e osso, com suas alegrias, suas aflições, suas ansiedades, suas angústias, suas incertezas. É o que vemos, por exemplo, na dolorosa constatação de Otto Lara Resende, em carta de 30 de setembro de I948: "Duro ofício, este de viver. Vivo a dizer que não me sinto apto para ele, que o ignoro, que não sei por onde começar". Ou, anos mais tarde, em carta de I7 de setembro de I957: "Que pena tudo! Bom, viver é sofrer." Angústia de que compartilha também Rubião, em carta de 20 de maio (provavelmente de I949): "Estou acostumado ao fracasso e a minha vida está marcada - duramente marcada - pelos insucessos".

Esse vislumbre fica mais evidente quando confrontado com os "perfis biográficos" que o organizador acrescentou imediatamente em seguida às cartas. Enquanto estas esboçam um retrato "vivo", em que os correspondentes aparecem em todas as suas fragilidades, suas contradições, suas aflições cotidianas, aqueles apresentam uma imagem post mortem, "cristalizada", estabilizada, em que se ressaltam os elementos da vida pública, os sucessos da carreira profissional, desaparecendo as nuanças que caracterizam a natureza humana.

Voltemos à correspondência. Como se lê no prefácio, "no conjunto epistolar que ora se apresenta, é possível notar três momentos". O primeiro, de I945 a I952, 
contempla o maior número de cartas e, poderíamos dizer, aquele em que a amizade e a formação de ambos os escritores se consolidam.

Podemos encontrar nessas cartas, além das considerações de leitura trocadas pelos missivistas, verdadeiros achados, que poderiam constituir, até mesmo, germes de narrativas, como se vê na carta de Murilo Rubião, de 23 de março de I949: "Não me abandonem, velhos amigos! A mensagem de vocês poderá evitar a transformação de um homem em árvore. Árvore sem flores”. Certamente um conto poderia ter surgido daí...

Nessa primeira parte, também estão as cartas que consolidam a amizade epistolar, com demonstrações de cuidado com o destinatário, como se lê logo na segunda carta do volume, escrita por Otto Lara Resende e datada de 3 de novembro de I947:

Recebi seu livro hoje. E hoje mesmo já o li todo. Acabo de fechá-lo neste momento. Parei a manhã me deliciando com ele, enquanto a chuva cai lá fora, disposta a não parar mais.

Minha intenção é escrever um artigo sobre seu livro. Se tivesse máquina aqui, faria agora mesmo esse artigo que estive coçando os dedos.

O missivista sente a necessidade premente de escrever ao destinatário, apresentando-lhe, de imediato, suas impressões de leitura e sua intenção de elaborar um artigo sobre o livro. O mesmo cuidado se nota em carta de Murilo Rubião, de 8 de setembro de I948: "O papel é péssimo, mas é o único e a ternura não admite novos adiamentos".

Como se nota, a necessidade de se corresponder é maior que qualquer impedimento: falta de uma máquina de escrever, papel ruim... É como se a carta recebida queimasse nas mãos do destinatário, enquanto não lhe dá resposta. É verdade que, por vezes, ela queima por meses a fio, ferindo as mãos daquele que a recebeu e não consegue lhe dar sequência, o que motiva cartas cujo objetivo é apenas justificar o incômodo silêncio que se interpôs entre os correspondentes, como lemos na escrita por Rubião em 25 de outubro de I948: "Não irei longe com esta carta. Ela se destina apenas a justificar o atraso da outra". Ou ainda, do mesmo remetente, em 23 de junho de I950: “Por diversas vezes, nos dois últimos meses, sentei na máquina para lhe escrever. Como nada tivesse de importante para contar, senão tristezas de dromedário longe do deserto, aproveitava o papel para reescrever contos”.

Por vezes, também, a sequência que se dá à correspondência não era a desejada, como lemos na carta de Lara Resende de 2 de agosto de I950: "Há já muito tempo, recebi uma carta sua, a que estou devendo resposta, sempre adiada. Mas não é dessa omissão que lhe quero falar agora; é de outra”.

Em outra ocasião, é a dúvida sobre a disponibilidade do destinatário que paira sobre o remetente, numa verdadeira demonstração de reafirmação do pacto epistolar, como se observa na carta escrita por Murilo Rubião em I9 de fevereiro de I949: "Não sei se minhas cartas chegaram às suas mãos. Também não sei se a sua vida atual permite o exercício epistolar".

Todos esses cuidados que lemos nas cartas do primeiro momento em que se divide a correspondência assentam suas bases e consolidam a amizade entre os missivistas, 
o que permite compreender os longos silêncios entre uma carta e outra não como descuido, mas como excessivo cuidado com o outro.

É, no entanto, do segundo momento do diálogo, entre I957 e I959, uma das cartas mais instigantes: a de número 62, enviada de Bruxelas a I7 de setembro de 1957 por Otto Lara Resende para Murilo Rubião, que, nessa ocasião, residia em Madri. Nela encontramos uma leitura minuciosa que o autor de $O$ braço direito fez do conto “Teleco, o coelhinho”, então ainda em gestação. O primeiro impulso que o leitor tem, após ler a carta, é buscar o conto de Murilo Rubião e confrontá-lo com as "pequenas observações", com as "notinhas à margem" de Lara Resende, que, segundo também se lê na correspondência, foram todas aceitas por Rubião. Ali também se descobre que o nome de uma das personagens sofreria modificação na forma definitiva do conto (Teresa chamava-se, então, na versão lida e comentada por Otto Lara Resende, Dalila...). Mais ainda, constata-se que uma das frases estampadas no conto ("a versatilidade é o meu fraco") foi uma das "anotações" enviadas na carta a Rubião. Consagra-se, assim, nesse exemplo, a correspondência como espaço privilegiado para a generosa circulação de ideias e para o amadurecimento da obra de um escritor. Desse modo, tal carta é uma preciosidade para os pesquisadores dos contos de Rubião, sobretudo aqueles dedicados à gênese da obra.

O terceiro momento, finalmente, englobando o longo período de I966 a I99I, contempla I9 documentos (numerados na edição de 77 a 95, sendo um cartão de visita, um curto bilhete, quatro telegramas, um rascunho de telegrama e doze cartas), que, confrontados com os dos períodos anteriores, podem apresentar menos interesse do ponto de vista literário, mas são fundamentais para a história da literatura e para a história de um dos mais importantes veículos de divulgação literária da segunda metade do século XX: o Suplemento Literário de Minas Gerais. Pela correspondência, tomamos conhecimento dos pormenores do projeto de publicação de um número do periódico que seria dedicado a Rubem Braga, mas que nunca foi aos prelos. Novamente, aqui, o leitor mais curioso passa a dar tratos à bola e imaginar como teria sido o caderno dedicado ao cronista de Ai de ti, Copacabana, com as contribuições previstas de Carlos Drummond de Andrade, Dalton Trevisan, Antonio Callado, Fernando Sabino, entre outros.

Completam o volume, além do prefácio e da correspondência propriamente dita, os perfis biográficos já mencionados e uma série de anexos - textos de circulação restrita, garimpados cuidadosamente pelo organizador. A edição, ricamente anotada, enriquecida por fotografias, apresenta, porém, pequeninos deslizes, "picuinhas" "sem nenhuma importância”, como poderíamos dizer, tomando de empréstimo expressões empregadas por Lara Resende em uma das cartas. Duas referências em nota de rodapé aludem a notas inexistentes no livro (a nota de número II8 recomenda "ver [...] nota 250"; a de I38, "ver nota 299"; o volume, contudo, tem ao todo 209 notas...), possivelmente resquícios de versão publicada na tese de doutorado do autor, na UFMG. Outra nota, a de número 7I, denuncia o diálogo entre o organizador e os editores: "Gentileza alterar o texto da nota para o seguinte [...]". Por fim, algumas notas talvez ficassem mais bem localizadas em outros pontos do livro: por exemplo, a nota biográfica sobre Israel Pinheiro, sogro de Otto Lara Resende, que aparece na carta 68, poderia ter aparecido na carta 43, salvo engano, a primeira menção feita ao 
ex-governador de Minas Gerais. “Coisa de somenos”, como diria Otto Lara Resende, fazendo-me lembrar o célebre aviso com que se fecha $O$ bibliófilo aprendiz, de Rubens Borba de Moraes: "Este livro foi redigido, composto, revisto e impresso por seres humanos e não por máquinas exclusivamente. Esse fato, por enquanto inelutável, explica os enganos e erros que contém”.

SOBRE O AUTOR

EMERSON TIN é professor de Língua Portuguesa

das Faculdades de Campinas (Facamp).

E-mail: emersontin@gmail.com 